\title{
Dispelling Negative Expectancies: The Impact of Interaction Goals and Target Characteristics on the Expectancy Confirmation Process
}

\author{
John M. Darley and John H. Fleming \\ Princeton University \\ JAMES L. HILION \\ University of Michigan \\ AND \\ William B. Swann, JR. \\ University of Texas at Austin \\ Received September 23, 1986
}

\begin{abstract}
The present study examined the impact of the interaction goals of perceivers and the characteristics of targets of a negative expectancy on the expectancy confirmation process. Perceivers were led to expect that their future interaction partner might have difficulty performing well under pressure. Perceivers were
\end{abstract}

The order of authorship is alphabetical; each author contributed equally. This research was supported in part by National Institute of Mental Health Trainiing Grant 5-T32MH $18021-01 / 02$ to Princeton University and was conducted as the second author's master's thesis under the direction of the first author. The preparation of this article was partially completed while John M. Darley was a fellow at the Center for Advanced Study in the Behavioral Sciences. He is grateful for the financial support provided by the National Science Foundation (BNS-8011494) and the John D. and Catherine T. McArthur Foundation. Also while this research was conducted, William B. Swann, Jr., was a visiting fellow at Princeton University supported by a research scientist development award (MH00498) from the National Institute of Mental Health. We gratefully acknowledge the assistance of Joel Cooper, William Hirst, Edward Jones, Dale Miller, and the members of the Social Psychology Research Seminar who commented on earlier drafts of this manuscript. The authors also thank Eric Bowman, Dan Gilbert, and Roger Kreuz for their assistance as the game players. Requests for reprints should be sent to Dr. John M. Darley, Department of Psychology, Green Hall, Princeton University, Princeton, NJ 08544. John H. Fleming is now at the University of Minnesota. MN. 
also placed in an interaction setting that made one of two interaction goals relevant: whereas some were encouraged to consider the partner as a possible teammate for a cooperative game; others were encouraged to have a casual conversation. Orthogonal to the interaction manipulation, subjects interacted with a target whose expectancy-relevant characteristics, if discovered during the interaction, could either support or refute the expectancy. Results indicated that the interaction goals perceivers inferred from the interaction setting influenced the extent to which they probed for information relevant to their negative expectancies. Their search strategies influenced what they discovered about the target, and these strategy-dependent discoveries, in turn, shaped their final impressions of the target. From this we argue that both the interaction goals of the perceivers and the characteristics of the targets of a negative expectancy are critical determinants of the fate of negative expectancies. 1988 Academic Press, Inc.

The potential destructiveness of negative expectancies has made them the focus of numerous psychological studies. Considerable evidence indicates that negative expectancies can channel social interaction in ways that cause the negative expectancies to come true (Darley \& Fazio, 1980; Jussim, 1986; Rosenthal \& Rubin, 1978; Snyder, 1981, 1984). Thus, for both reasons of theoretical interest and societal policy relevance, the efforts devoted to understanding expectancy confirmation processes have been warranted.

Expectancy confirmation research has focused on a number of variables (see Jones, 1986; Miller \& Turnbull, 1986; Rosenthal \& Rubin, 1978, for reviews), but the resurgence of interest in motivational constructs that has characterized recent theory and research on social perception and social interaction (see Higgins \& Bargh, 1987; Showers \& Cantor, 1985; Sorrentino \& Higgins, 1986) has been slower to spread to accounts of expectancy confirmation processes. In this article we attempt to add to the theoretical understanding of those processes by showing how the concept of interaction goals is a particularly useful construct on which to draw for a theoretical account of expectancy confirmation processes. The importance of interaction goals in person perception is not a new suggestion (Jones \& Thibaut, 1958), but it is one that has not been incorporated into most accounts of the expectancy confirmation process.

Similarly, Swann and his colleagues (Swann, 1984; Swann \& Ely, 1984; Swann \& Read, 1981) have pointed out that studies of the expectancy confirmation process have also tended to overlook the impact of the characteristics of the targets of negative expectancies in determining the outcome of the process. Recent research suggests that this omission may be a significant one. Swann and Ely (1984) showed that perceivers completely revised their expectancies when they interacted with targets who possessed self-concepts that were inconsistent with the perceivers' expectancies. Hilton and Darley (1985) demonstrated that targets who were made aware of the existence of a negative expectancy about them were 
able to overcome the expectancy. In the current study, we examined the influence of both the perceiver's interaction goals and the expectancy confirming and disconfirming characteristics of the target on the expectancy confirmation process.

The importance of perceivers' goals has been recognized in at least one aspect of the expectancy confirmation process. Jones and Thibaut (1958) suggested that a perceiver's goals served to place him or her in a particular cognitive set through which information would be differentially processed. Numerous studies have demonstrated such goal-induced differences in perceivers' processing of identical information (Erber \& Fiske, 1984; Fleming \& Kraut, 1986; Showers \& Cantor, 1985; Sorrentino \& Higgins, 1986; Srull \& Wyer, 1986; Wyer \& Srull, 1986). Thus it is clear that motivational factors play an instrumental role in guiding the processing of social information. Yet almost no attention has been paid to the effects of perceivers' goals on the gathering of the information on which the perceivers' later judgments are based.

Subjects' information solicitation strategies play an important part in interpersonal interactions, and because they influence the information the interactants receive about each other, they are likely also to influence the resulting perceptions of interactants (see Snyder, 1981; Snyder \& Swann, 1978; Trope \& Bassok, 1982, 1983; Trope, Bassok, \& Alon, 1984). To specify how goals are likely to affect the information solicitation process, and via that, the expectancy confirmation process, Hilton and Darley (1985) have suggested that different types of interactions make different specific interaction goals relevant for perceivers. These goals combine with the information the perceiver may have about the target, the social constraints of the interaction setting (roles and norms), and other contextual factors, to yield an interaction strategy that the perceiver will pursue as the interaction unfolds.

The hypotheses tested in this study were, first, that the interaction goals of the perceivers (determined by the context of their particular interaction) would determine whether they would search or not search for expectancy-relevant information. Second, that the different goal-induced interaction strategies of the perceivers, because they led to different patterns of discovery about the targets' characteristics, would bring about different final impressions of the targets. The actual characteristics of the target, which either confirmed or disconfirmed the expectancy, would be discovered only by interactants whose goals caused them to devise interaction tactics that probed for expectancy-relevant information. Third and somewhat more speculatively, the discovery of expectancy-relevant target information would have its greatest impact on perceivers' evaluations of the target when it tended to refute the expectancy.

To these ends, all perceivers were given an expectancy from which it might be reasonably inferred that the person with whom they would 
be interacting might be unable to perform adequately in stressful situations. Half of the subjects were told that the other was a potential partner for a game (the "potential partner" conditions). They saw videotapes of others playing a game from which it could be inferred that doing well at the game required participants to think quickly on their feet. The remaining subjects were simply told to have a casual interaction with the person (the "casual conversation" conditions). Orthogonal to this manipulation, half of the subjects interacted with a target whose expectancyrelevant characteristics, if discovered by the perceiver during the interaction, could confirm the expectancy (the "frantic" target), and half interacted with a target whose expectancy-relevant characteristics, if discovered, could disconfirm the expectancy (the "composed" target).

We expected that the goal induced in the "potential partner" conditions would cause subjects to devise interaction tactics aimed at discovering how well the other functioned under pressure, and that we would be able to detect these tactics by the subjects' frequent asking of the negative, but expectancy-relevant questions. In other words, when their goals called for it, perceivers" would ignore the costs associated with particular interaction behaviors (such as asking potentially awkward questions) and would engage in those behaviors to achieve their goals-they would ask more expectancy-relevant questions than subjects in the casual conversation conditions. Because of this pattern of information solicitation, we expected that subjects in the potential partner conditions would be more apt to discover the actual characteristics of the target. Therefore, these subjects should be likely to realize that the characteristics of the "frantic" target confirm their negative expectancies, but the characteristics of the "composed" target do not. In contrast, we expected that subjects in the casual conversation conditions would fail to uncover evidence relevant to the expectancy and would consequently remain close to their initial expectations in both the "frantic" and "composed" target conditions.

\section{METHOD}

\section{Subjects}

Forty male Princeton University undergraduate volunteers were contacted to participate in a study of social communication. All subjects were randomly assigned to one of the four conditions in this 2 ("casual conversation" vs "potential partner") $\times 2$ (expectancyconfirming ["frantic"] target vs expectancy-disconfirming ["composed"] target) design.

\section{Procedure}

Subjects participated individually. Upon arrival, all subjects were told that they were to participate in a study concerned with the effects of familiarity on verbal communication and speech patterns. Subjects in the casual conversation conditions were further told that they would be holding a brief casual conversation with a stranger. These subjects were told that we were interested in the different vocal patterns that people emit in conversation with acquaintances and with strangers and that other subjects would be holding brief 
conversations with acquaintances. On the other hand, subjects in the potential partner conditions were told that they would be holding brief conversations with several students whom they did not know in order to select a partner for a cooperative game similar to the television show, The $\$ 25,000$ Pyramid. They were also told that these individuals were unaware that they were being considered for the game. Because the game that they were to play was portrayed as a method for obtaining verbal recordings, none of the subjects was offered any incentive for good performance in the game.

\section{Introduction of the Expectancy}

Next, subjects completed a brief information sheet, ostensibly for their partners' benefit. In addition to asking for some basic demographics (e.g., age, hometown, high school attended), this sheet asked whether the subjects had participated in the Princeton Voluntary Personality Inventory (PVPI) and if so, whether they had received their results. In fact. the PVPI is a nonexistent inventory that was invented to set the stage for the introduction of the expectancy. When subjects reached the items asking about the PVPI the experimenter explained that the PVPI was a personality inventory designed and tested, in large part, at Princeton University. Ile further explaincd that the PVPI was being used in all current research studies. All subjects were then asked to read an information pamphlet describing the PVPI. In this pamphlet, the PVPI was described as a recently initiated research instrument comprising a number of objective tests as well as an interview with a clinical psychologist. The PVPI was described as reasonably reliable and valid, but still under development and thus vulnerable to some inaccuracy. Participation in the testing was explained to be contingent on public access to all of the test results.

All subjects then read their partuers' background information sheets. These sheets always indicated that their partners had taken the PVPI, but had not received their results. The experimenter then explained that although nonreceipt of the test results was unusual, there would be no problem associated with showing them the PVPI results, given the public access agreement.

The PVPI results, presented as a narrative written by a clinician, suggested that although intelligent, their partner might have difficulty performing under pressure and was likely to become overly emotional in some stressful situations.

\section{The Videotaped Game}

All subjects then watched videotapes of a cooperative game. Subjects in the potential partner conditions believed that the game was the one they would be playing later. (Casual conversation subjects were asked to watch the tapes as a favor to the experimenter while ostensibly waiting for their partner to complete a questionnaire.) The game itself was modeled after the television game show. The $\$ 25,000$ Pyramid. and consisted of one player (the "sender") providing both verbal and nonverbal clues to a second player (the "receiver") so that the receiver might correctly guess seven items from a selected category (e.g., types of food) within a $60-\mathrm{s}$ time limit.

The purpose of the videotapes was to suggest that a team's successful performance in the game was largely dependent upon the performance of the sender. One tape depicted a successful sender who showed no signs of stress-related performance decrements and whose team correctly identified all seven words within the allotted time. The other tape portrayed a nervous, unsuccessful sender who was obviously shaken by pressure. frequently stuttered and glanced at the timer, and whose partner managed to identify correctly only four of the seven items in the allotted time.

After watching the videotapes the subjects were escorted to the room from which the conversations were conducted, seated at a large table upon which stood a microphone and speaker, and given a stack of 21 index cards. 


\section{Question Selection}

On each card was a question that the subjects could choose to ask their partners during the conversation. All subjects were first asked to decide, on a scale from 0 to 15 , how much they would like to ask each question during the interview. The set of 21 questions comprised 7 negative questions that probed the expectancy, 7 neutral questions that might come up in casual conversation, and 7 rather negative questions that probed personal attributes different from those relevant to the expectancy (see Appendix A). By making the questions that were relevant to the expectancy negative in tone, we made the experimental situation model one of that class of situations in which there are social costs (i.e., potential embarrassment or awkwardness) incurred by probing for expectancy-relevant information. After rating the 21 questions, the subjects were asked to select 8 of the questions to be asked during the conversation.

\section{The Manipulation of Target Behavior}

In order to maintain the consistency of responses across the subjects, a simulated interaction was used in place of a live interaction partner. We prepared 28 response tapes. Seven of these tapes were neutral responses to the seven neutral questions that the subjects might ask. Seven other tapes were ambiguous, but primarily disconfirming, responses to the seven negative, expectancy-irrelevant questions. The remaining 14 tapes were paired alternate responses to the seven negative, expectancy-relevant questions. For each expectancyrelevant question, one response (the "frantic" target) confirmed the expectancy and the other response (the "composed" target) disconfirmed it. We attempted to equate these responses for approximate duration and forcefulness (see Appendix B for examples of the target's responses). Depending on condition, the subjects heard either the frantic or the composed target respond to all of the expectancy-relevant questions they chose to ask. The frantic target generally admitted to possessing the negative characteristic implied by the question, gave an example, and repeated his admission that he possessed the negative characteristic. The composed target denied the implication that he possessed the negative characteristic, told of some incident that supported this denial, and repeated his assertion that he functioned well under pressure. Both the frantic and composed targets' answers were delivered in a calm, even manner to make the expectancy-relevant responses as comparable to the neutral responses as possible.

\section{The Simulated Interaction}

It was explained that because the study was about verbal behavior, the conversation would take place over an intercom system. On a signal from the experimenter the subject read the first question he had chosen and then waited for the response. Depending on treatment condition, the expcrimenter loaded and played the appropriate tape to respond to the subject's query. We used two cassette tape players, alternating between them for each tape-recorded response. In this way, we preserved the order of the subject's questions and provided a situation that very closely resembled a genuine dyadic interaction. After the partner finished responding to the question, the subject proceeded to the next question. Subjects followed this pattern of question/response until all eight questions had been asked and eight responses had been provided. During debriefing none of the subjects reported suspecting that the target was not "live" and all seemed convinced that the interaction had been genuine.

\section{The Dependent Measures}

Question-asking differences. The primary dependent measure of interest was the subjects' choices of questions to ask during the interaction. Specifically, we were interested in the number of negative. expectancy-relevant questions that subjects posed to the target. In 
addition, we examined subjects' ratings of each of the 21 possible questions in terms of how much they would have liked to ask that question during the interaction.

Subjects' ratings of their interaction partners. Following the interaction, subjects completed a questionnaire designed to assess their perceptions of their interaction partners. The questionnaire comprised twelve 15-point bipolar trait scales, as well as seven "behavioroid" items designed to tap subjects' perceptions of their partner. Of the 12 trait items, 5 were relevant to the present research. The 7 remaining trait items were filler items and were included to ensure that the pattern of results predicted for the relevant measures did not generalize to irrelevant trait domains. The two measures of final impression of interest were a standardized index of the bipolar trait scales that assessed the degree to which the subjects judged their partners as susceptible to stress, and a standardized index of 5 of the 7 "behavioroid" measures that we expected to tap a similar "performance under pressure" construct. The 2 remaining "behavioroid" measures, "How likely do you think the person with whom you just interacted would be to commit a social blunder?" and "Would you characterize this person as someone you would like to get to know better?" were included as filler items.

The expectancy-relevant trait scales were coded so that a high score (15) corresponded to the presence of the stress susceptible trait and a low score (1) corresponded to the presence of the opposite (stress unsusceptible) trait, with unmarked, neutral scale midpoints. Four of the five expectancy-relevant trait scales were found to be highly intercorrelated (Emotionally Stable/Unstable, Stable/Flighty Under Pressure, Calm/Anxious, and Composed/Frantic) and provided an overall reliability coefficient that was sufficiently high (standardized $\alpha=.94$ ) to justify combining the responses on these measures. ' Therefore. the responses of these four trait measures were standardized and averaged to form a Stress Susceptihility index in which higher standardized scores indicate greater susceptibility.

Four of the five "performance under pressure" measures, "How likely do you think your partner would be to "crumble" under pressure?" "Is your partner the type of person you would want to rely on for a quick response in a high pressure situation?" "How anxious, relative to your friends, was your partner?" and "How likely would you be to choose this person as a partner in a game requiring quick decisions in high-pressure situations?" were obtained using 15-point scales with a low score (1) corresponding to extremely unlikely and a high score (15) correspondiing to extremely likely with unmarked. neutral scale midpoints. The fifth item, "Given that a normal resting pulse rate is 72 beats per minute, what is your best estimate of your partner's pulse rate during this experiment?" was an open-ended item that asked subjects to estimate their partner's pulse rate during the experiment, with the presumption that higher estimated pulse rates indicated evidence of higher levels of stress. These five items also produced an overall reliability coefficient (standardized $\alpha=.90$ ) sufficiently high to warrant combining subjects' responses on these measures. The responses on these five "hehavioroid" measures were standardized and averaged to form a Stress Performance index. On this index, higher standardized scores indicate a greater likelihood of poor performance under pressure. Upon completion of the questionnaire, all subjects were probed for suspicion, thoroughly debriefed, and paid for their participation.

\footnotetext{
'We had originally expected a fifth scale, Easy-going/Uptight, to form part of this index, but it did not correlate highly with the other four scales and, when included, dropped the overall reliability coefficient to .64 . Consequently, this item was not included in the computation of the Stress Susceptibility index. In addition, no significant effects emerged on this item when it was analyzed separately.
} 
TABLE 1

Mean Numbers of Questions Asked and Subjects' Ratings of the Questions' DesirabilitTy

\begin{tabular}{|c|c|c|c|}
\hline \multirow[b]{2}{*}{$\begin{array}{l}\text { Interaction }{ }^{a} \\
\text { goal }\end{array}$} & \multicolumn{3}{|c|}{ Type of question } \\
\hline & $\begin{array}{l}\text { Negative } \\
\text { expectancy } \\
\text { relevant }\end{array}$ & $\begin{array}{l}\text { Neutral } \\
\text { expectancy } \\
\text { irrelevant }\end{array}$ & $\begin{array}{l}\text { Negative } \\
\text { expectancy } \\
\text { irrelevant }\end{array}$ \\
\hline \multicolumn{4}{|c|}{ Number of questions asked ${ }^{h}$} \\
\hline Casual conversation & 1.75 & 4.40 & 1.85 \\
\hline Potential partner & 5.45 & 1.35 & 1.20 \\
\hline \multicolumn{4}{|c|}{ Desirability of questions' } \\
\hline Casual conversation & 8.32 & 11.31 & 7.90 \\
\hline Potential partner & 13.02 & 6.55 & 7.49 \\
\hline
\end{tabular}

" $n=20$ per interaction goal condition.

${ }^{b}$ The total number of questions that each subject was allowed to ask during the interview was eight.

Desirability ratings were made on a 15 -point scale $11=$ Would not at all like to ask. 15 = Would very much like to ask).

\section{RESULTS}

\section{Question-Asking Differences}

Subjects were instructed to select 8 questions from the pool of 21 possible questions. We expected that potential partner subjects would ask more questions designed to probe the expectancy than subjects in the casual conversation conditions, despite the risk of social awkwardness those questions might carry. Consistent with this prediction, a one-way analysis of variance showed that potential partner subjects, on average, asked more of the negatively phrased, expectancy-relevant questions ( $M$ $=5.45)$ than did casual conversation subjects $(M=1.75), F(1,38)=$ $52.71, p<.001$. The relevant means are presented in Table 1 .

Subjects' ratings of the 21 questions in terms of how much they would have liked to ask each question during the interaction were scored so that higher ratings indicated a greater desire to ask the question. Subjects' likability ratings of the expectancy-relevant questions, the neutral questions, and the negative irrelevant questions were averaged separately, and these scores were then submitted to separate one-way analyses of variance. Consistent with the question selection results, these analyses revealed that potential partner subjects rated the negative, expectancy-relevant questions as significantly more desirable than did their casual conversation counterparts, $F(1,38)=37.78, p<.001$. Moreover, the potential partner subjects also found the neutral questions significantly less appealing to ask than did the casual conversation subjects, $F(1,38)=41.84, p<$ 


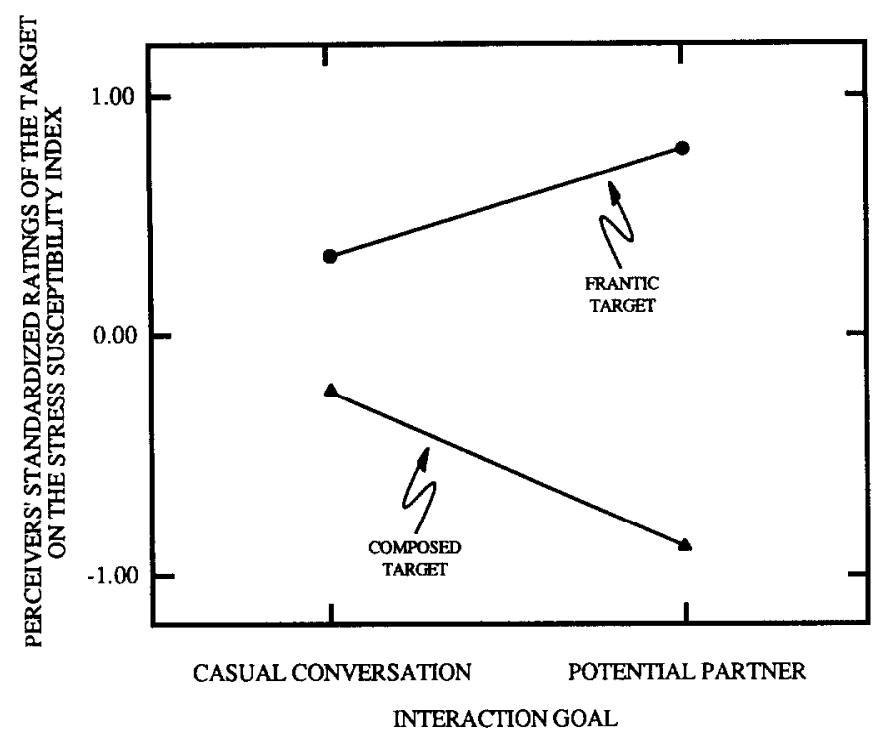

FIG. 1. Perceivers' ratings of the target on the Stress Susceptibility index.

.001 . No differences emerged on the subjects' ratings of the negative, irrelevant questions. Subjects in the potential partner conditions found these questions no more appealing than did casual conversation subjects, $F(1,38)<1$, n.s.

\section{Subjects' Ratings of Their Interaction Partners}

\section{The Stress Susceptibility Index}

Our second prediction was that the information-search tactics implemented in response to the subjects' different interaction goals would interact with the characteristics of the target to produce divergent final impressions of him. Specifically, we predicted that in the "composed target" conditions, potential partner subjects would rate the target as composed but casual conversation subjects would rate him as frantic. In contrast, we expected that in the "frantic target" conditions perceivers would always rate the target as frantic, regardless of the treatment condition to which they had been assigned.

A two-way analysis of variance performed on the Stress Susceptibility index provides support for the predictions. Frantic-target subjects rated the target higher on the Stress Susceptibility index $(M=0.55)$ than did composed-target subjects $(M=-0.55), F(1,36)=24.60, p<.001$. As can be seen in Fig. 1, the interaction between the type of target and the interaction goal was significant, $F(1,36)=6.15, p<.02$. Simple effects analyses showed that among subjects who interacted with the composed target, potential partner subjects rated the target significantly lower on 
the Stress Susceptibility index $(M=-0.87)$ than did subjects in the casual conversation condition $(M=-0.22), F(1,36)=4.36, p<.05$. No reliable differences emerged among subjects who interacted with the frantic target (potential partner $M=0.77$, casual conversation $M=$ $0.33), F(1,36)=2.01$, n.s.

Another way of analyzing these data, although not independent of the analysis reported above, is illuminating. Among subjects in the potential partner conditions, subjects who interacted with the frantic target rated him significantly higher on the Stress Susceptibility index $(M=0.77)$ than did those who heard the composed target $(M=-0.87), F(1,36)$, $=27.67, p<.001$. Only a marginally reliable difference emerged among subjects in the casual conversation conditions; frantic-target subjects tended to rate the target as marginally more susceptible to stress $(M=$ $0.33)$ than composed-target subjects $(M=-0.22), F(1,36)=3.08, p$ $<.09$.

\section{The Stress Performance Index}

We expected a similar pattern of results to emerge on the Stress Performance index as emerged on the Stress Susceptibility index. Again, this index was coded so that a high standardized score represented a greater likelihood of poor performance under pressure. Consistent with our predictions, a similar pattern of results emerged for the Stress Performance index. A two-way analysis of variance revealed that frantictarget subjects expected their partner to perform more poorly under pressure $(M=0.52)$ than their composed-target counterparts $(M=$ $-0.53), F(1,36),=30.06, p<.001$. The interaction was significant, $F(1,36)=9.42, p<.01$, with all of the means in the anticipated directions. Simple effects analyses yielded findings comparable to the stress susceptibility index.

\section{Stress-Irrelevant Trait Scales}

As previously mentioned, the other trait scales were included to ensure that the predicted pattern of results emerged only on those trait dimensions bearing directly on the stress susceptibility expectancy, and not on unrelated trait dimensions. ${ }^{2}$ A standardized index of these eight items (standardized $\alpha=.75$ ) produced no reliable differences among treatment conditions. In addition, when we examined each of these items separately, none produced the pattern of means predicted for the expectancy-relevant indices.

\footnotetext{
${ }^{2}$ The seven remaining trait scales were: Friendly/Unfriendly, Warm/Cold, Bright/Dull, Intelligent/Unintelligent, Predictable/Unpredictable, Good-natured/Irritable, and Sociable/Unsociable. None of these scales was correlated with the Stress Susceptibility or Stress Performance indices.
} 
In addition, neither of the questions expected to be orthogonal to the expectancy at hand, "How likely do you think the person you just interviewed would be to commit a social blunder?" and "Would you characterize this person as someone you would like to get to know better?" produced any significant differences among treatment conditions.

\section{Path Analyses: The Mediating Role of Question-Asking Strategies}

In order to examine the role that the question-asking strategies played for perceivers interacting with composed and frantic targets, we conducted path analyses of the causal relations between perceivers' interaction goals, the number of expectancy-relevant questions they asked during the interaction, and their ratings of the target on the Stress Susceptibility and Stress Performance indices. ${ }^{3}$ These analyses were performed separately for perceivers who interacted with the frantic and composed targets and the resultant path diagrams are presented in Fig. 2.

These analyses suggest that expectancy confirmation and disconfirmation are asymmetrical processes: for subjects who received disconfirming responses to their probes (composed target subjects), the question-asking tactics they employed (the number of expectancy-relevant questions they asked), coupled, of course, with the responses elicited from the other individual, were significantly related to the extent to which they revised their impression of the target. For frantic target subjects (those for whom the responses to the questions asked were generally confirming of the original expectancy), the relationship between the number of expectancyrelevant questions asked and the measures of final impression was not statistically significant. For these subjects, asking additional expectancyrelevant questions simply resulted in responses that were consistent with the impression generated by the original expectancy. These additional responses may have provided additional information, but none that was inconsistent with that which the subjects had previously received. Consequently, this additional information had no noticeable impact on their final impressions of the target.

\footnotetext{
Another way of examining whether expectancy confirmation and disconfirmation are symmetrical processes in this study is to covary out the effects of the number of expectancyrelevant questions asked from the standard analysis of variance and see if the observed differences in ratings of final impression disappear. (See Kenny, 1979, pp. 200-205, for an explanation of the use of analysis of covariance in establishing mediation in an experimental design. A good example of the use of the technique can be found in Insko et al., 1973.) To test this, we performed a covariance analysis on subjects' Stress Susceptibility index ratings of their partners for subjects in the composed-target conditions. The number of negative, expectancy-relevant questions asked was used as the covariate. This yielded a marginally significant effect for the covariate, $F(1,17)=3.44, p<.08$, and the previously significant difference in the standardized ratings of final impression between the treatment conditions disappeared (casual conversation adjusted $M=-0.46$, potential partner adjusted $M=-0.64), F(1,17)<1$, n.s.
} 

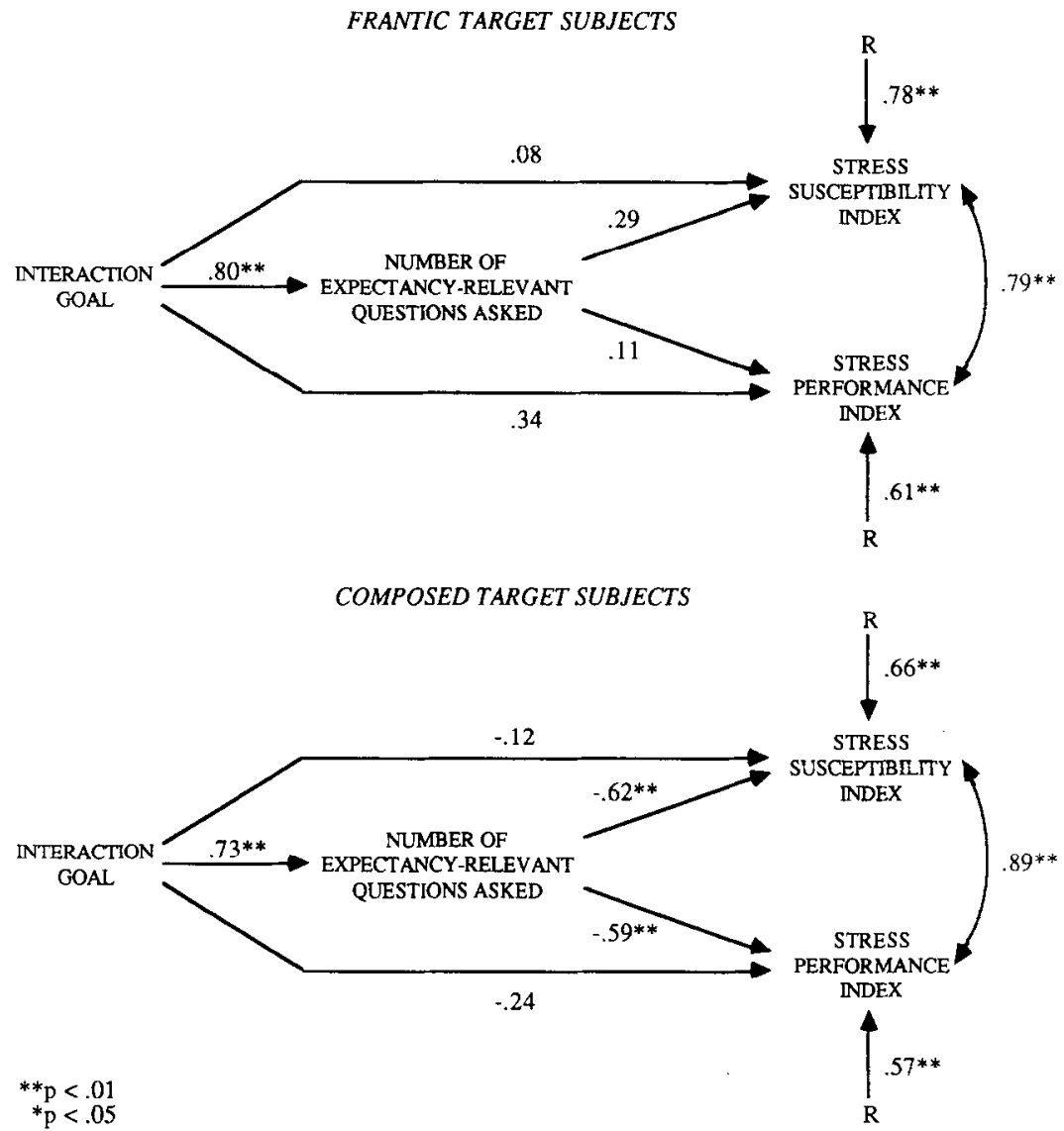

Fig. 2. Path analyses of the direct effect of perceivers' interaction goals and the mediational effect of their question-asking strategies on final impressions of the target, separately for frantic and composed target subjects. All nonasterisked $p$ values are nonsignificant at $p$ $>.09$.

\section{DISCUSSION}

In psychology textbooks and perhaps in lectures on the subject, the expectancy confirmation effect is sometimes characterized as an established and ubiquitous phenomenon. Because the first generation of studies on the effect was designed to demonstrate its existence, they may have contributed to this perhaps overgeneralized impression. It is worth noticing that many of these first set of studies, as well as some recent demonstrations (Curtis \& Miller, 1986), entirely appropriately, arranged that the target and the perceiver would interact in some variant of a "casual conversation" setting-one in which the perceivers' goals for the interaction would not be likely to cause them to probe for the truth of the negative expectancy 
and thus would not lead them to discover information that might disconfirm the expectancy. This interaction context was therefore configured to be hospitable to the production of expectancy confirmation effects (e.g., Snyder, Tanke, \& Berscheid, 1977; but cf. Kelly \& Stahelski, 1970; Word, Zanna, \& Cooper, 1974, for exceptions). Having amply demonstrated the existence of the effect, however, it is perhaps now time to examine the process more closely to see whether any important factors have been overlooked.

As we expected, our final impression results were largely (but not exclusively) a result of the subjects' information solicitation tactics. That is, in the present study subjects chose the questions to ask their interaction partners in advance. Their selections, in turn, determined what information became available to them. By having the participants set their question sequence in advance, we make it obvious that their interaction tactics played a major causal role in determining their final impressions of the target, and that the causal sequence began with the goal induction, and ran through their information solicitation tactics to the final impressions.

In future experiments, it would be useful to examine situations in which perceivers can responsively alter their information-solicitation strategies. In these situations, in which participants are free to alter their questionasking strategies, we would expect the discovery of expectancy-inconsistent information (a) to be more likely than the discovery of expectancyconsistent information to trigger a search for further expectancy-relevant information (Pyszczynski \& Greenberg, 1981) and (b) to push the perceiver to reevaluate, in a stepwise fashion, the veracity of the expectancy.

A third aspect of our results deserves emphasis. The final impressions were determined not only by the search strategies of the perceivers, but by the responses provided by the (in this case, simulated) targets. In the present case, we chose to model an interaction situation in which the perceiver has power-he or she controls the content and flow of the interaction. It should be clear, however, that in a complete model of goal-driven interaction, we must include the interaction goals of the target, as manifest in the information that the target chooses to provide in response to the probes of the perceiver. The process is one of bidirectional influence, a fact that should not be obscured because we controlled the content of the target's responses in this study. When both the perceiver and the target are free to pursue their purposes in an interaction, we would expect each interactant's goals to influence their interaction tactics. For example, when targets are highly motivated to be perceived correctly by others, they may actually channel the interaction in ways that assert their own self-concepts, neutralizing the perceiver's attempts to avoid those issues (see Swann \& Ely, 1984; Swann \& Read, 1981).

Notice that overall, this analysis suggest that expectancy perseverance is a frequent outcome of interaction. In some interactions, notably those 
in which the perceiver's goal prevents or inhibits a search for expectancyrelevant information, the perceiver does not search for expectancy-relevant information and the expectancy is likely to persist, regardless of the characteristics of the target that, if discovered, might have forced the perceiver to alter the expectancy. In other interactions, the perceiver searches out expectancy-relevant information. Depending on whether confirming, ambiguous, or disconfirming evidence is discovered, the expectancy will be retained or revised. The reader will notice that this verbally characterizes a matrix composed of six cells that result from the combination of the two types of interaction goals used in this study and three possible types of target characteristics. If we assume further that ambiguous information will be assimilated to an expectancy (Darley \& Gross, 1983), five of these six cells are likely to lead to a result that is consistent with expectancy confirmation. This predominance of confirmation may go some way toward explaining why a good many studies have found evidence for expectancy confirmation, while only recently has the question of expectancy disconfirmation arisen (Miller \& Turnbull, 1986; Rothbart, 1981; Swann, 1984).

In summary, when will negative expectancies survive our encounters with the targets of those expectancies to form the basis for self-fulfilling prophecies? Our findings suggest that at least two factors interact to determine the persistence of negative expectancies: the interaction goals of the perceiver and the characteristics of the target. When the perceiver's interaction goals fail to motivate a search for expectancy-relevant target characteristics, the expectancy will persist. When the interaction goals motivate a search for expectancy-relevant characteristics and the target actually possesses thosc negative characteristics, the expectancy will persist. Only when interaction goals motivate a search for expectancyrelevant target characteristics and the target possesses discoverable, expectancy-discrediting characteristics, will the negative expectancy be abandoned. These data, then, bring us one step closer to specifying when negative expectancies will be retained and when they will be discarded. The major point for the understanding of person perception is that what a person may learn about another depends very heavily on that person's purpose in the interaction. It is in this sense that we suggest that person perception and expectancy confirmation processes are dependent on the interpersonal goals and interaction tactics of the interactants. 
APPENDIX A

List of Questions Available to Perceivers during the Interaction

\section{Content}

Negative, expectancy-relevant items

Have you ever blown an exam because you panicked when you noticed time running out?

Do you ever lose control when you feel under the gun?

Are you easily flustered?

Do you tend to crumble under pressure?

Can you remember a time when it could be said that at best you stammered through an oral presentation?

Can you remember a time when your emotions hindered a performance?

Do you hate doing things in which you have to act quickly?

Neutral, expectancy-irrelevant items

Have you traveled much?

Are you involved in any extracurricular activities?

Is there anywhere in particular you'd like to live?

Do you like school so far?

Did you do anything interesting last summer?

Do you like the residential college system?

Would you describe yourself as an optimist?

Negative, expectancy-irrelevant items

Do you think others would describe you as insensitive?

Do you consider yourself a procrastinater?

Would you describe yourself as manipulative?

Can you remember a time when you made a social faux pas?

Do you find it hard to "put yourself in other people's shoes?"

Do you think your opinion is of little value?

Would you describe yourself as mechanically inept? 


\section{APPENDIX B \\ Selected Target Responses to Subjects' Questions during the Interaction}

Frantic target response

Composed target response

Expectancy-relevant question: Do you ever lose control when you feel "under the gun?"

Uh . . . sort of . . yeah, I guess. I remember in high school I had a couple of papers due and I remember that as the deadline got closer and closer I sat in front of the blank paper and all I could think about was the deadline. I threw pencils around the room and things, but finally $I$ just had to ask for an extension. Once I wasn't "under the gun" anymore and the time pressure was off I was fine. In fact, I thought they were some of my better essays. But boy, as long as I had that deadline staring me in the face, I just went berserk. I couldn't think at all. So ... uh . . yea, I suppose so.

Negative expectancy-irrelevant question:

Do you think that others would describe you as insensitive?

Um . . . (laugh) . . . no. I don't think others would describe me as insensitive. They might not describe me as the warmest human being ever to grace the earth, but I don't think they would describe me as insensitive. I mean. I don't go around kicking dogs in the street, and I don't go up to people who are depressed and say "Gee, isn't life gloom and doom?" I consider myself to be pretty average on sensitivity. I respond to others. If I think they need encouragement, I'm there trying to encourage them. Uh ... in fact, it's very hard for me to imagine someone thinking that I'm insensitive. So no, I can't imagine someone doing that. No.
I tend to be the kind of person who maintains control no matter what. It doesn't matter whether I feel under the gun or not. Uh . . . when I'm under the gun I just assert myself a little more, buckle down a little harder, and really get going. I mean, last week I had an essay due and it was an essay where we had a couple of days to write it in. I kind of put it off until the last night and I only had a couple of hours to write it in. I guess some people would panic in a situation like that, really worrying about whether they were going to get it done or not. But I knew all along that $I$ was going to get it done. That was never the question. I think I did a pretty good job on the essay. Basically, I just buckled down and wrote it, and turned it in. I don't know' what my grade on it is, but I think it will be pretty good. . , so I don't think I tend to lose control. I've never lost control when I was "under the gun."

Neutral expectancy-irrelevant question:

Would you describe yourself as an optimist?

Um . . Gee . . I I don't know if I would describe myself as an optimist. I guess if I had to describe myself, I would describe myself as a realist. I mean I don't walk around thinking all the world is bright and cheery. But I don't run around waiting for the sky to fall or anything like that. I think I try to approach things from a realistic perspective and take things as they come. So, I wouldn't describe myself as an optimist, but I wouldn't describe myself as a pessimist either. I think I am a realist. 


\section{REFERENCES}

Curtis, R. C., \& Miller, K. (1986). Believing another likes or dislikes you: Behaviors making the beliefs come true. Journal of Personality and Social Psychology, 51, 284290.

Darley, J. M., \& Fazio, R. (1980). Expectancy confirmation processes arising in the social interaction sequence. American Psychologist, 35, 867-881.

Darley, J. M., \& Gross, P. (1983). A hypothesis-confirming bias in labeling effects. Journal of Personality and Social Psychology, 44, 20-33.

Erber, R., \& Fiske, S. T. (1984). Outcome dependency and attention to inconsistent information. Journal of Personality and Social Psychology, 47, 709-726.

Fleming, J. H., \& Kraut, R. E. (1986). At face value: Correspondence, goal-induced discounting, and accuracy in interpreting facial displays of emotion. Unpublished manuscript, Princeton University.

Higgins, E. T., \& Bargh, J. A. (1987). Social cognition and social perception. In M. R. Rosenzweig \& L. W. Porter (Eds.), Annual Review of Psychology (Vol. 38). Palo Alto, CA: Annual Reviews, Inc.

Hilton, J. L., \& Darley, J. M. (1985). Constructing other persons: A limit on the effect. Journal of Experimental Social Psychology, 21, 1-18.

Insko, C. A., Thompson, V. D., Stroebe, W., Shaud, K. F., Pinner, B. E., \& Layton, B. D. (1973). Implied evaluation and the similarity-attraction effect. Journal of Personality and Social Psychology, 25, 297-308.

Jones, E. E. (1986). Interpreting interpersonal behavior: The role of expectancies. Science, 234, 41-46.

Jones, E. E., \& Thibaut, J. (1958). Interaction goals as bases of inference in interpersonal perception. In R. 'Tagiuri \& L. Petrullo (Eds.), Person perception and interpersonal behavior (pp. 151-178). Stanford, CA: Stanford Univ. Press.

Jussim, L. (1986). Self-fulfilling prophecies: A theoretical and integrative review, Psychological Review, 93, 429-445.

Kelley, H. H., \& Stahelski, A. J. (1970). Social interaction basis of cooperators and competitors' beliefs about others. Journal of Personality and Social Psychology, 16, 66-91.

Kenny, D. A. (1979). Correlation and causality. New York: Wiley.

Miller, D. T., \& Turnbull, W. (1986). Expectancies and interpersonal processes. In M. R. Rosenzweig \& L. W. Porter (Eds.), Annual review of psychology (Vol. 37). Palo Alto. CA: Annual Reviews, Inc.

Pyszczynski, T. A., \& Greenberg, J. (1981). Role of disconfirmed expectancies in the instigation of attributional processing. Journal of Personality and Social Psychology, 40, 31-38.

Rosenthal, R., \& Rubin, D. B. (1978). Interpersonal expectancy effects: The first 345 studies. The Behavioral and Brain Sciences, 3, 377-415.

Rothbart, M. (1981). Memory processes and social beliefs. In D. L. Hamilton (Ed.), Cognitive processes in stereotyping and intergroup behavior (pp. 145-181). Hillsdale. NJ: Erlbaum.

Showers, C., \& Cantor, N. (1985). Social cognition: A look at motivated strategies. In M. R. Rosenzweig \& L. W. Porter (Eds.), Annual review of psychology (Vol. 36, pp. 275-305). Palo Alto, CA: Annual Reviews, Inc.

Snyder, M. (1981). Seek, and ye shall find: Testing hypotheses about other people. In E. T. Higgins, C. P. Herman, \& M. P. Zanna (Eds.), Social cognition: The Ontario symposium (Vol. 1). Hillsdale, NJ: Erlbaum.

Snyder, M. (1984). When belief creates reality. In L. Berkowitz (Ed.), Advances in experimental social psychology (Vol. 18, pp. 248-305). New York: Academic Press. 
Snyder, M., \& Swann, W. B., Jr. (1978). Behavioral confirmation in social interaction: From social perception to social reality. Journal of Experimental Social Psychology, 14, $148-162$.

Snyder, M., Tanke, E. D., \& Berscheid, E. (1977). Social perception and interpersonal behavior: On the self-fulfilling nature of social stereotypes. Journal of Personality and Social Psychology, 35, 656-666.

Sorrentino, R. M., \& Higgins, E. T. (1986). Handbook of motivation and social cognition. New York: Guilford.

Srull, T. K., \& Wyer, R. S., Jr. (1986). The role of chronic and temporary goals in social information processing. In R. M. Sorrentino \& E. T. Higgins (Eds.), Handbook of motivation and social cognition ( $\mathrm{pp}$. 503-549). New York: Guilford.

Swann, W. B., Jr. (1984). The quest for accuracy in person perception: A matter of pragmatics. Psychological Review, 91, 457-477.

Swann, W. B., Jr., \& Ely, R. J. (1984). A battle of wills: Self-verification versus behavioral confirmation. Journal of Personality and Social Psychology, 46, 1287-1302.

Swann, W. B., Jr., \& Read, S. J. (1981). Self-verification process: How we sustain our self-conception. Journal of Experimental Social Psychology, 17, 351-372.

Trope, Y., \& Bassok, M. (1982). Confirmatory and diagnosing strategies in social information gathering. Journal of Personality and Social Psychology, 43, 22-34.

Trope, Y., \& Bassok, M. (1983). Information gathering strategies in intuitive interviewing. Journal of Experimental Social Psychology, 19, 560-576:

Trope, Y., Bassok, M., \& Alon, E. (1984). The question lay interviewers ask. Journal of Personality, 52, 90-106.

Word, C. H., Zanna, M. P., \& Cooper, J. (1974). The nonverbal mediation of self-fulfilling prophecies in interracial interaction. Journal of Experimental Social Psychology, 10, 109-120.

Wyer, R. S., Jr., \& Srull, T. K. (1986). Human cognition in its social context. Psychological Review, 93, 322-359. 